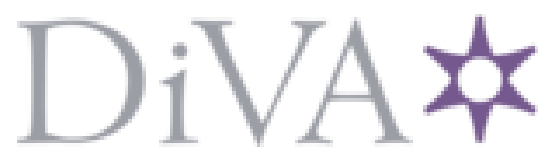

http://www.diva-portal.org

\title{
Postprint
}

This is the accepted version of a paper published in Journal of Cleaner Production. This paper has been peer-reviewed but does not include the final publisher proof-corrections or journal pagination.

Citation for the original published paper (version of record):

Missimer, M., Robèrt, K-H., Broman, G. (2016)

A Strategic Approach to Social Sustainability - Part 2: A Principle-based Definition.

Journal of Cleaner Production

http://dx.doi.org/10.1016/j.jclepro.2016.04.059

Access to the published version may require subscription.

N.B. When citing this work, cite the original published paper.

Permanent link to this version:

http://urn.kb.se/resolve?urn=urn:nbn:se:bth-1 1907 


\section{A Strategic Approach to Social Sustainability - Part 2: A Principle-based Definition}

This is an accepted manuscript of the article.

Please cite the article as: Missimer, M., et al., A strategic approach to social sustainability e Part 2: a principle-based definition, Journal of Cleaner Production (2016), http://dx.doi.org/10.1016/j.jclepro.2016.04.059

(C) 2016. This manuscript version is made available under the CC-BY-NC-ND 4.0 license http://creativecommons.org/licenses/by-nc-nd/4.0/ 


\title{
A Strategic Approach to Social Sustainability - Part 2: A Principle-based Definition
}

\author{
Merlina Missimer \\ PhD, Blekinge Institute of Technology, Sweden. \\ mis@bth.se, Corresponding author \\ Karl-Henrik Robèrt \\ Professor, Blekinge Institute of Technology, Sweden \\ khr@bth.se \\ Göran Broman \\ Professor, Blekinge Institute of Technology, Sweden \\ gbr@bth.se
}

\begin{abstract}
The vast and growing array of concepts, methods and tools in the sustainability field imply a need for a structuring and coordinating framework, including a unifying and operational definition of sustainability. One attempt at such framework began over 25 years ago and is now widely known as the Framework for Strategic Sustainable Development. However, as with the larger sustainability field, the social dimension of this framework has been found to not be sufficiently science-based and operational and thus in need of further development. In this two-part series an attempt at a science-based, operational definition of social sustainability is presented. In part 1 a systems-based approach to the social system was presented, based on extensive literature studies as well as conceptual modelling sessions using the Framework for Strategic Sustainable Development as the guiding structure. The focus of that study was on the essential aspects of the social system that need to be sustained, namely trust, common meaning, diversity, capacity for learning and capacity for selforganization. The aim of this second paper is to identify and present overriding mechanisms by which these aspects of the social system can be degraded, thereby finding exclusion criteria for re-design for sustainability. Further literature studies, conceptual modelling sessions and initial testing of this prototype with partners in academia, business and NGOs were performed. Based on the understanding of the essential aspects of the social system and the identified overriding mechanisms of degradation of these, a hypothesis for a definition of social sustainability by basic principles is presented. The proposed principles are that in a socially sustainable society, people are not subject to structural obstacles to: (1) health, (2) influence, (3) competence, (4) impartiality and (5) meaning-making. Overall, the two papers aim to provide a hypothesis for a definition of social sustainability, which is general enough to be applied irrespective of spatial and temporal constraints, but concrete enough to guide decision-making and monitoring. It is also a further development of the social dimension of the FSSD, which practitioners and researchers have requested for some time and can act as a support towards better integration of social sustainability in
\end{abstract}


many other fields, e.g., sustainable product innovation, sustainable supply chain management, sustainable transport system development, and others.

Keywords: strategic sustainable development; social sustainability; social system; systems thinking; sustainability principles. 


\section{Introduction}

Sustainable development (SD) has been a prominent part of the global political discussion for almost 30 years (World Commission on Environment and Development, 1987; United Nations, 2015). Today, there is a vast amount of definitions, terms, approaches, concepts, methods and tools. For overviews, see the papers by Hopwood et el. (2005), Glavik and Lukman (2007), Lozano (2008), BenEli (2012), Chasin (2014), and Amini and Bienstock (2014). Yet, the field is still often criticized for its vagueness (e.g., Jacobs 1999, McKenzie 2004, Ben-Eli 2012) and a clearer approach has been requested (Huesemann 2001, Robèrt et al. 2002, Johnston et al. 2007, Marsden et al. 2010).

Paper 1 (Missimer et al., in this issue) of this two-part series started out with presenting the Framework for Strategic Sustainable Development (FSSD) as a useful approach to dealing with this challenge. Its usefulness is due to:

- The systems approach, which helps prevent sub-optimization, where a solution to one issue may otherwise cause other issues somewhere else or later on in time.

- Its scientific basis, which utilizes the most relevant, cross-culturally reliable and up-to-date knowledge to understand systems and make decisions.

- Its principle-based definition of success, which allows for a clear definition of the goal of sustainability that is not just based on current trends, can be agreed upon even by large groups of people and still be supplemented with more context-specific goals.

- The sustainability principles being phrased as constraints for re-design, thus allowing for creativity and innovation for the systematic re-design which our human structures need; and

- The ability of the framework to strategically make use of supplementary support for sustainable development when necessary. Once the FSSD has been used to identify the big-picture gap to sustainability, and to develop an overriding strategy to bridge the gap, rational choices of more specific methods and tools for the development of indicators, monitoring, decision support, cross-sector community building, and communication can be made.

However, it has also been acknowledged that the social dimension of the FSSD needs further development (Missimer et al., 2010; Missimer 2013). This underdevelopment of the social dimension of sustainability is also prevalent in the larger field of sustainability (Littig and Griessler 2005, Kunz 2006, Colantonio et al. 2009, Cuthill 2010, Dempsey et al. 2011).

Missimer et al. (in this issue) built on this assessment of the FSSD and used conceptual modelling, i.e., modelling of concepts found in literature using the structure of the FSSD as a lens. More specifically, this means that extensive literature reviews were conducted, key concepts distilled and then the five levels of the FSSD were used to understand the relationships of these key concepts from a strategic sustainable development perspective. This approach allows the systems perspective on planning to evolve from a dynamic and iterative dialogue between the system level, which describes the system of study, and the success level, which describes the goal or purpose in the system. It is this iterative 'ping-pong' between levels that was 
the base of the conceptual modelling. Paper 1 presented the final version of multiple iterations of this dialogue at the systems level and presented the following aspects of the social system as essential to sustain (they cannot be systematically degraded) from a social sustainability point of view: trust, common meaning, diversity, capacity for learning and capacity for self-organization. The aim of this second paper is to identify and present overriding mechanisms by which these aspects of the social system can be degraded, and to formulate operational sustainability principles as exclusion criteria for redesign of society towards social sustainability.

\subsection{Defining Sustainability}

It should be pointed out that the whole process of attempting an operational definition of sustainability starts out from a normative stance (a value statement). The Brundtland definition of sustainability - "... development that meets the needs of the present without compromising the ability of future generations to meet their own needs" (World Commission on Environment and Development, 1987) is in this paper taken as a basis for such a normative stance. Wanting this to happen cannot be derived from scientific knowledge or proven right or wrong by scientific methods. That this is at all desirable is a normative stance that each person needs to decide for herself/himself to embrace or not.

Once this normative stance is accepted, scientific knowledge and scientific methods can be used to draw conclusions: "if this is what we want, on what conditions can it be achieved?" Given that humans are dependent on the ecological and the social system to meet our needs, what are the essential aspects of the ecological and social systems that need to be sustained (or restored) in order to not systematically undermine the capacity of people to meet their own needs, now and in the future. And, what are the overriding mechanisms by which these essential aspects can be degraded?

Sustainability is thus about the elimination of mechanisms of systematic degradation of essential aspects of both the ecological and the social system. Since thresholds in complex adaptive systems are difficult to identify, it makes sense to define sustainability this way - to not have a basic design and operation of society that implies a systematic deviation from the above-mentioned desirable state. This provides boundary conditions for redesign of our currently unsustainable basic design and operation of society, as a frame for any vision without being prescriptive at the level of detail, the scenario level, within the boundary conditions. Defining sustainability through such basic boundary conditions allows for and can even stimulate innovation.

\subsection{Is a Single Definition Appropriate?}

A common argument as regards especially social sustainability is that vagueness and a pluralism of definitions are appropriate and preferable over a single definition, because of the complexity of the topic and that therefore a common definition is impossible or undesirable (McKenzie 2005, Kunz 2006, Dempsey et al. 2011, 
Boström 2012). Proponents of this stance (e.g., Lehtonen 2004, 211) argue that "different geographical and temporal scales as well as situational contexts require their own frameworks, which do not necessarily provide a coherent picture, but a mosaic of partly contradicting views of reality". They propose that sustainability can only be defined in a local context through participatory processes, with engagement from all stakeholders (Davidson 2009, Dempsey et al. 2011).

The arguments can be challenged on several grounds. Jacobs' (1999) criticism, that vagueness allows unsustainable action to be couched and presented as sustainable, holds also for social sustainability. Another challenge comes up with context-specific definitions. Acknowledging that in many ways humanity has become a global network, if actions in one area of the world can have large effects in areas far away from the location of action, are then many context-dependent definitions created by smaller communities enough to ensure that larger sustainability problem are not created somewhere else?

Furthermore, similar arguments were used to discourage attempts to find a definition of ecological sustainability to support structuring of analyses and planning. Counter to these arguments, the existing definition of ecological sustainability of the FSSD has shown to be operational at any scale, irrespective of the specifics of activities in different organizations and regions (e.g. Broman and Robèrt, in this issue).

The sustainability principles of the FSSD are designed to be generally applicable and at the same time concrete enough to guide analyses, planning, innovation and selection, design and a coordinated use of supplementary concepts, methods and tools. The approach to define success in a complex system in this way, i.e., by basic principles or 'boundary conditions for redesign', effectively addresses also the conservative bias that is sometimes leveled at the social sustainability field (e.g Marcuse 1998). As the state of sustainability is defined by principles rather than the specifics of a scenario, it is not in fact a conservative state to maintain a certain configuration; nor does it exclude a participatory approach to defining what an organization or a community wants together. Well thought-through boundary conditions, applied in a participatory manner, allow and encourage groups, organizations and communities to create visions together and cooperate in nonprescriptive manners to work towards the principle-framed visions. As long as visions (maybe described as scenarios) remain within principled sustainability boundaries, a participatory approach is possible and can be very useful. In fact, processes to cocreate visions within boundary conditions, and to plan ahead towards such visions, should also contain an openness to develop and sharpen the boundary conditions based on data from real-life learning experiences. This is indeed the way the phrasing of all the sustainability principles of the FSSD have evolved, through many iterations, as evident from many peer-reviewed scientific publications.

Others also advocate against context-specific definitions. Hodge and Hardi (1997, 10) argue that a clear conceptual framework is vital for assessment purposes as it helps to identify relevant indicators that can be adjusted to a specific context if needed. Partridge $(2005,4)$ summarizes

"It is not necessarily useful to only think of sustainability as contextdependent. While it is useful to apply the idea to a particular object (like forestry, fishing or human wellbeing for example), I want to suggest that the real potential of sustainability as an idea is as an integrating framework - a means for considering the relationships 
between different dimensions, rather than just assessing the sustainability or otherwise of a single element."

Finally, the fact that a complex goal in a complex system may be difficult to derive, e.g., defining sustainability in the social system, is not a satisfactory rational for not trying. Even a failure in this regard, would produce some learning. It is based on these arguments that the research set out to derive a set of social sustainability principles.

\section{Methods}

The two tandem papers of this study aim to provide a prototype of a new approach to social sustainability within the FSSD. As described in Paper 1, the methods employed were mostly literature studies and conceptual modelling (Robinson 2006, Brooks 2007, Kotiadis and Robinson 2008, Jaccard and Jacoby 2010) using the FSSD as a structuring lens. Specific focus was on the system and success level of the FSSD and the overall research was guided by the idea to allow the systems perspective on planning to evolve from a dynamic and iterative dialogue between these two levels of the FSSD. It is this iterative 'ping-pong' between levels that was the base of the conceptual modelling.

As mentioned, a unique aspect of the FSSD is that any definition of success is required to be within basic sustainability principles. The principles for ecological sustainability were derived by asking the following question: by what overriding mechanisms, upstream at the level of first approximation in chains of causality, do human activities set off the myriad of downstream impacts that will destroy the ecological system? Literature studies provided empirical knowledge of the functioning of the ecosystem and the sustainability challenge in this regard (level 1 of the FSSD). This knowledge together with conceptual modelling sessions with groups of experts lead to a first attempt to come up with overriding mechanisms of degradation that would explain ecological unsustainability. A myriad of downstream impacts were clustered in a few upstream first-order mechanisms. Thereafter, a "not" was inserted for each mechanism to form first-order sustainability principles, designed as exclusion criteria for redesign. Next the generality of this attempted principled definition of ecological sustainability was tested on more empirical data of the ecosystem and the sustainability challenge related to it. Also the utility and usability of the definition were tested in real-life application of the FSSD with various organizations. All of this gave rise to a new and more refined definition, which was tested again, and so on. For a further description of the FSSD and its application, see Broman and Robert (in this issue).

It was found, during the learning process, that to be functional within the FSSD, the set of basic principles for sustainability must have the following characteristics (e.g. Ny, 2009)

- Necessary for sustainability, i.e., to avoid imposing unnecessary requirements and to avoid confusion over elements that may be debatable.

- Sufficient for sustainability, i.e., the principles taken together should cover all relevant aspects.

- General, i.e., people from various societal sectors and scientific disciplines should be able to understand and use them. 
- Concrete, i.e., capable of guiding problem solving and innovation.

- Non-overlapping, i.e., mutually exclusive to facilitate comprehension and monitoring.

The aim for the derivation of the social sustainability principles was to follow a similar approach.

\subsection{Literature Review}

After the initial literature review described in Paper 1, it became obvious that the dynamics of trust needed to be better understood. This term returned frequently, and it was obvious that it is key for healthy social systems. Key literature in the field was surveyed (e.g., Luhmann 1979, Giddens 1984, Baier 1986 , Luhmann 1988, Coleman 1990, Giddens 1990, Giddens 1991, Putnam 1993, Fukuyama 1995 , Mayer et al. 1995, Kramer and Tyler 1996, Miztal 1996, Hollis 1998, Sztompka 1999, Warren 1999, Gambetta 2000, Luhmann 2000, Putnam 2000, Cook 2001, Lahno 2001 , Fukuyama 2002, Hardin 2002, Nyquist Potter 2002, Uslaner 2002, Caldwell and Clapham 2003, Ostrom et al. 2003, Rothstein 2005, Tilly 2005, McLeod 2006, Castelfranchi and Falcone 2010) and the vast amount of literature from different disciplines that discuss the benefits of trust underscored the importance of this element. This study led to the conclusion that the topic of focus for sustaining trust should be trustworthiness (see the reasoning in, e.g., Meijboom 2008). This, in turn, led to a search for theories of trustworthiness, specifically the kind of theories that do not only discuss trustworthiness at a general level, but provide empirical evidence for a list of elements of trustworthiness. The elements were especially important for the understanding and subsequent modelling of mechanisms of destruction of trust. The literature search for theories of trustworthiness was conducted using google scholar with the search term "allintitle: trustworthiness". Articles with seemingly relevant titles (e.g. trustworthiness in the sense of validity of results was excluded) were skimmed to look for theoretical constructs of trustworthiness. If no theoretical construct was presented as a base for the article, the article was excluded. Once a construct was mentioned more than 3 times it was more deeply investigated. This process led to three theories chosen for their wide use and empirical support presented in the results section (see section 3.1.2 -3.1.4).

This theoretical understanding led to a first round of modelling to derive a first set of social sustainability principles focusing on the erosion of trust. This first set was then checked against the other essential elements identified in paper 1 - common meaning, diversity, capacity for learning and capacity for self-organization and whether the attempted principles also covered the mechanisms of destruction for those elements (which required further literature review, e.g. to understand the nuances of 'a sense of meaning'). Finally, the set of candidate principles was checked against the five criteria which boundary conditions need to adhere to to be useful for backcasting and redesign for sustainability, i.e., necessary, sufficient, general, concrete and nonoverlapping (see above).

\subsection{Conceptual Modelling}


The conceptual modelling took place in numerous workshops with the authors of this paper. In addition, the modelling was expanded and improved via a dozen workshops with a diverse and large group of participants from different sectors and disciplines natural scientists from different disciplines, social scientists from different disciplines, managers in business and municipalities as well as politicians. The main objective was to find and test generic mechanisms and principles, beyond the differences in norms and values that the various groups bring. The different backgrounds were required to make sure that the terms and aspects from literature, modelled along the FSSD structure, were understood across disciplines and perceived as generic or basic. This approach follows from the long-term objective of FSSD-informed work: to cocreate, across sectors and disciplines, strategic transitions to towards sustainability.

After the core group came up with a candidate set and felt ready for testing the hypothesis, the group was widened to the next circle. The researchers in the core group wanted to know if the phrasing was understood as intended by other researchers from other disciplines. Criticism and new ideas and references were collected, which led to more modelling and an adjusted hypothesis, again assessed by the above five criteria. Then the next circle was addressed. The final circle for testing included people from business, municipalities and other practitioners. The aim was to see how the proposed principles were understood by them, whether the proposed principles triggered ideas that were felt to be helpful to identify current problems as well as future solutions from a strategic sustainability perspective in the respective organizations, i.e., whether the principles work as intended, and whether the practitioners agreed that the principles are 'necessary', 'sufficient', 'general', 'concrete' and 'non-overlapping'

This process model: (i) having a core team understanding exactly what the objective is, i.e., designing a framework for strategic sustainable development that is generic across disciplines, sectors, norms and values, yet detailed enough to be operational, (ii) reaching out to get criticism from larger and larger groups to test the generic qualities of the hypotheses, but (iii) without losing track of the original idea of the framework, was also used in the consensus work in earlier iterations of the FSSD. It was also applied for consensus work regarding various specific topics, such as energy, agriculture, etc. See Robèrt (2002) for more elaboration on this.

Throughout this process another modelling process took place; namely the kind of modelling where the researchers would take contemporary social issues and test whether they could be clustered under the derived mechanisms of destruction. In this way, unemployment, e.g., could be understood as a combination of an obstacle to health, meaning the lack of basic economic means to take care of oneself, and an obstacle to meaning-making, meaning the individual lost their role and with it their sense of place in the world. This kind of modelling served to make sure that the mechanisms of destruction did really cover contemporary social sustainability issues.

\subsection{Circles of Participants}

The hypothesis derived from literature studies resulted in workshops, moving from the core to the periphery of the widening circles of colleagues, peers and experts. A) The core group was constituted by the authors of this paper. B) The next circle 
included colleagues in the sustainability group at Blekinge Institute of Technology (BTH) comprised of researchers with backgrounds in business administration, anthropology, product development, etc., and students from the Master's in Strategic Leadership towards Sustainability with backgrounds from a wide array of disciplines. C) The next circle included external scholars across various disciplines, e.g. Political Science (Scholars from the Quality of Government Institute at Gothenburg University), Business, Management and Organizational Dynamics (Scholars from Acadia University in Nova Scotia and the University of Pennsylvania), Design (Scholars from the Strategic Innovation Lab at the Ontario School of Arts and Design), Computer Science (Scholars from Otago Polytechnic's College of Enterprise and Development as well as the University of Toronto), Modelling (Scholars from Lund University), Green Chemistry (Scholars from Carnegie Mellon University and Brunel University). D) The outermost circle included people from municipalities and other public organizations, e.g., representatives from the Municipality of Karlskrona, Landstinget Blekinge, Stockholm Läns Landsting, from various businesses including Aura Light International, Max Hamburgerrestauranger, Scandic Hotels, Sleep Well, The Human Element, Stockholms Hamnar, Riksbyggen, Skanska, Vasakronan and other practitioners, e.g., practitioners from The Natural Step international network.

The details of the methodology for the entire research project, which these papers are a part of, can be found in Missimer 2015.

\section{Results}

As described in the methods section, the essential elements identified in paper 1 (trust, common meaning, diversity, capacity for learning and capacity for self-organization) were taken one by one and explored more deeply to understand and derive mechanism of destructions for these. The vast literature on trust made it a good candidate to start with in the modelling process before cross-checking against the other essential aspects. This is also the order in which it is presented in this section.

As pointed out, describing an iterative process in a linear fashion of a paper can be challenging. Due to this, it is sometimes necessary to also discuss the reasoning for a particular result in this section.

\subsection{Principles for Social Sustainability derived from Trust}

Meijboom $(2008,91)$ defines trust as an

"attitude towards (collective) humans that enables an agent to cope with situations of uncertainty and lack of control, by formulating a positive expectation towards another agent, based on the assessment of the trustworthiness of the trusted agent". He adds (ibid, 28) that "trust includes a sincere belief about the trustworthiness of the trusted agent that is informed by the available evidence. However, trust is 
more than cognitive, more than a mental conviction based on the available evidence. It further includes an emotional component".

For Lewis and Weigert (1985) trust is characterized by a "cognitive 'leap' beyond the expectations that reason and experience alone would warrant - they simply serve as the platform from which the leap is made" (971). Mayer et al. (1995) incorporate the emotional component by adding a vulnerability component defining trust as the willingness of a trustor to be vulnerable to the actions of a trustee based on the expectation that the trustee will perform a particular action. They argue that "making oneself vulnerable is taking risk. Trust is not taking risk per se, but rather it is a willingness to take risk" (Mayer et al. 1995, 712). Thus, trust is defined as an attitude that enables an agent to cope with situations of uncertainty and lack of control, by making themselves vulnerable based on positive expectations towards another agent, derived from the assessment of the trustworthiness of the trusted agent. Bews and Martins $(2002,14)$ describe trust as a dynamic phenomenon that unfolds over two stages. The first stage depends on 'pre-trust' conditions; the second depends on the perception of trustworthiness of the person to be trusted. This second part continues throughout the length of the relationship, while the first is of shorter duration.

\subsubsection{Trust Necessitates Trustworthiness}

As trust has a strong emotional component and involves a cognitive leap it is not something that can be controlled or forced, but must rather be invited and earned. This explains the strong focus on trustworthiness in the definitions above. Meijboom et al. (2006) discuss this in relation to consumer trust:

"You cannot make others trust you. This, however, does not imply that [....] trust is an unmanageable problem. It shows that we had better approach the issue from the question of why a consumer would trust someone else. If we do so, we notice that trust raises the question whether the other person is worth being trusted. This emphasizes that lack of trust is a problem of the one who wants to be trusted rather than of the trustor (432)."

Many authors agree with this statement and claim that the essential factor in creating trust is actually trustworthiness (Hardin 1996, Tullberg 2008).

The understanding of the importance of trustworthiness lead to search for theories of trustworthiness as elaborated in the methods section, the results of which are presented below.

\subsubsection{Components of Trustworthiness}

According to Mayer et al. (1995), trustworthiness is made up of three components:

Ability/Competence: Ability is the group of skills, competencies, and characteristics that enable a party to have influence within some specific domain.

\footnotetext{
${ }^{1}$ For support on the emotional component also see (Jones 1996; Lahno, 2001).
} 
Motivation of Benevolence: A Motivation of Benevolence is the extent to which a trustee is believed to want to do good to the trustor.

Integrity: Integrity is the consistency in the other party in adhering to espoused values and the acceptability of these values (Mayer and Norman 2004).

These three components have since been validated empirically (e.g., Schoorman et al. 1996, Engelbrecht and Cloete 2000, Bews and Martin 2002, Mayer and Gavin 2005, Colquitt et al. 2007) and adopted in subsequent models (McKnight et al. 1998; also see Colquitt et al. 2007). Finally, they have been found to be the most recurrent factors in trustworthiness studies (Roy and Shekhar 2010).

\subsubsection{Trusting Teams - Fundamental Interpersonal Relations Orientation}

Another theory of inter-personal trust is the Fundamental Interpersonal Relations Orientation (FIRO) (Schutz 1958, 1992, 1994), which has a long track-record of being practically used in high-performance teams, e.g., squad teams in the army and alike. According to FIRO, three dimensions of reciprocal interpersonal relations are necessary and sufficient to explain well-functioning teams based on trust and trustworthiness, namely if each group member feels that he/she is...

1. Being Significant ... opposed to feeling unimportant, meaningless, and of no value.

2. Being Competent... opposed to feeling inept and unable to cope.

3. Being Liked...opposed to feeling unappreciated.

...the level of trust is high and the group functions well in tough situations.

\subsubsection{Creating Trust through Trustworthy Institutions}

The above components of trust and trustworthiness are discussed in connection to inter-personal trust. Rothstein (2005) as well as Wollebaeck and Selle (2008) believe that, at a societal level, institutional trust is by far the most important predictor of social (generalized) trust. Rothstein (2005) argues that because institutions design the rules and incentives, which govern behaviour at the individual level, it is the institutional design that is the leverage point for fostering trust or mistrust within a society. He argues that specifically (i) effective and (ii) impartial governmental institutions that implement public policy lead to trust-generation in citizens.

The role of public institutions is so important because they are responsible for the governance of the entire system and they are key in creating social norms around interaction. Rothstein and Stolle $(2008,444)$ explain that "states, for example, enable the establishment of reliable contracts between citizens in that they provide information and monitor legislation about contracts, and enforce rights and rules that sanction lawbreakers, protect minorities and actively support the integration and participation of citizens". Institutions fall as key actors at level 1 of the FSSD. 
However, their behavior can support or not support compliance with the sustainability principles at level 2.

Having explored trust and trustworthiness at various scales of social systems and presented them briefly, the next section moves on to attempt a first set of social sustainability principles.

\subsubsection{Deriving Principles}

As a reminder, for sustainability principles to work in the FSSD, they need to be necessary, sufficient, general, concrete and non-overlapping. They should also be phrased as exclusion criteria for re-design. The latter implies that they represent basic upstream mechanisms of destruction, in this case basic upstream mechanisms to destroy the essential aspects of the social system, equipped with a "not".

As one of the criteria for the principles is being 'general' (to be applicable in any arena, at any scale, by any member in a team and all stakeholders, regardless of field of expertise, to allow for cross-disciplinary and cross-sector collaboration) some abstraction was needed to fit this requirement. Both FIRO and Mayer et al.'s components for trusting groups and trustworthiness presented above, operate at an interpersonal, not a global, social level. These were therefore extrapolated to a higher level without the essence being lost, as follows.

For FIRO, e.g., one can note that an individual cannot expect to be seen as 'significant', 'competent' and 'liked' in person by people who do not know anything about the individual. However, one can have the general stance that every human being ought to be respected as a person. The concrete expression of that would be to respect the right of each individual to uphold health, i.e., to avoid injury and illness (physically, mentally and emotionally) in the short and long term.

Being 'significant' is also a doubtful expression in the larger social context; you cannot say about people you do not know anything about that they are significant. But you can claim their right to have an impact in this context. The best translation to the larger social system might then be influence, which is a more generic term regardless of scale of the social system.

The term competence seems to be applicable to both the smaller and the larger system and therefore does not need to be changed.

A similar abstraction can be done for Mayer et al.'s principles. While competence can remain, 'benevolence' might be hard to assess at a scale larger than social systems where people know each other. Benevolence at a higher level, similarly to 'being liked', might be expressed as respecting the right of each individual to uphold health.

'Integrity' in the Mayer et al. meaning (consistency based on espoused and acceptable values) sticks out a bit. For one, the aspect of consistency falls at the strategic guidelines level of the FSSD. However, the aspect of acceptable values remains. This will be returned to below. 
Trustworthy institutions as a mechanism to create trusting social systems are described as effective (meaning competent at achieving their goals) and impartial (Rothstein 2005). This mirrors the aspect of competence mentioned before and adds the aspect of impartiality.

This is also supported by research around equality and trust. Wilkinson and Pickett (2009) show that trust is higher in more equal societies ${ }^{2}$. Although equality and impartiality are not equivalent, this supports the importance of impartiality as a design principle as partiality is a way to create high levels of inequality.

In summary, the reasoning on trust leads to a first hypothesis for a definition of social sustainability:

In a socially sustainable society, people are not subject to structural obstacles to ...

SSP 1....health.

(This means that people are not exposed to social conditions that systematically undermine their possibilities to avoid injury and illness; physically, mentally or emotionally, e.g., dangerous working conditions or insufficient wages.)

SSP 2. ...influence.

(This means that people are not systematically hindered from participating in shaping the social systems they are part of, e.g., by suppression of free speech or neglect of opinions.)

SSP 3. ...competence.

(This means that people are not systematically hindered from learning and developing competence individually and together, e.g., by obstacles for education or insufficient possibilities for personal development.)

SSP 4. ...impartiality.

(This means that people are not systematically exposed to partial treatment, e.g., by discrimination or unfair selection to job positions.)

Structural obstacles describe social constructions - political, economic and cultural which are firmly established in society, upheld by those with power (political, economic or other forms), and which are, due to a variety of dependencies, difficult to overcome or avoid by the people exposed to them.

\subsection{Principles for Social Sustainability derived from the Other Essential Aspects}

\footnotetext{
${ }^{2}$ Measured by income equality.
} 
Paper 1 also identified common meaning, diversity, capacity for learning and capacity for self-organization as essential aspects to sustain in the social system. The question is now whether the above-proposed principles are sufficient also as regards these aspects.

\subsubsection{Common Meaning}

As pointed out in paper 1, humans are a meaning-making species and therefore by default create a sense of meaning. A sense of meaning is strongly linked to the individual's mental and emotional health (Klinger 1998) and structural obstacles acting to suppress meaning-making, could therefore be understood through the mechanism of not respecting the individual's right to uphold health.

However, basic principles, designed as boundary conditions for redesign, should address primary and not indirect effects. If structural obstacles are primarily perceived as being in the way of meaning-making this needs to be addressed in its own right.

From the point of view of social capital and keeping a society together, common meaning was also an essential aspect identified in paper 1. The importance of common meaning is also supported by the aspect of integrity mentioned by Mayer et al., i.e., consistency based on espoused and acceptable values. It is defined as standards of behavior, and rings very close to a common meaning in the sense of having decided together what is important in a group of people or society at large.

The importance of common meaning expressed as purpose is not the least evident when looking at sub-systems. In a complex system with independent agents, these agents have many choices regarding what sub-system to affiliate with. A reason for existence may be serving a particular function, serving a function particularly well or having some other attribute that attracts people. This echoes the argument for a strong purpose in organizations in order to ensure their survival (e.g., Collins and Porras 2002).

Therefore another social sustainability principle is added to the list.

In a socially sustainable society, people are not subject to structural obstacles to ...

SSP 5. ...meaning-making.

(This means that people are not systematically hindered from creating individual meaning and co-creating common meaning, e.g., by suppression of cultural expression or obstacles to co-creation of purposeful conditions.)

\subsubsection{Diversity}

Diversity is mentioned in the literature as an aspect of adaptive capacity. In a social system, we are interested in diversity as regards characteristics such as gender, age, personality, skills, etc. It is diversity in this regard that "provides a mix of components 
whose history and accumulated experience help cope with change, and facilitates redevelopment and innovation following disturbance and crisis"(Folke et al. 2002, 19).

So, would this kind of diversity be assured through the above-mentioned social sustainability principles? We believe so. If people in general are not systematically hindered from influencing the social systems they are part of and from developing the competence they like, and if they are not systematically exposed to partial treatment, all the individual differences have opportunity to show up at the system level. It does not seem that another sustainability principle needs to be added to ensure diversity in the system.

\subsubsection{Capacity for Learning}

Learning is also mentioned as an aspect, which enables flexibility and development. This aspect seems to be covered by the principle around competence as learning comes through the individuals into the system. In addition, continued competence development includes the ability to learn and remain competent even as the environment changes and the definition of structural obstacles to competence therefore includes the barriers of development and learning.

Even though learning is a natural individual trait, the organizational learning literature comes to the conclusion that organizational or communal learning does not come naturally to us. To learn as a system we need to learn together. Lageroos $(2004,321)$ in this same vain comments, that

"learning can be stifled and the traditional patterns of an advanced
social system often do just that. As systems age, they tended to solidify
protocols that once worked, but may no longer work because the
environment has changed or because the protocol has become
corrupted over time without anyone noticing. Yet, the people who
achieved power by the old system naturally tend to believe in it."

However, the above social sustainability principles can address these issues. The principle around influence allows individual learning to transfer to the system level and the principle around impartiality ensures that everyone's ideas in the learning process are valued in an impartial way. The principle around meaning-making ensures that there is no systematic hindrance to the process making sense of the world together and in the process learn from it. Overall, this should ensure that learning can emerge at the system level.

\subsubsection{Capacity for Self-organization}

The last essential aspect of the social system, coming from the literature, was that of self-organization - the ability of the system to organize itself without a predetermined intent and structure. In a social system this would refer to individuals being able to organize themselves into different structures to address a certain goal. All living systems are naturally self-organizing in their healthy form. This implies that as long as the above social sustainability principles are complied with, particularly no 
structural obstacles to influence, competence and impartiality, there should be no reason why groups of people would not be able to do so.

This concludes the investigation for upstream mechanisms of destruction of the essential aspects of the social system identified in paper 1 .

\subsection{A zero Hypothesis for Social Sustainability Principles}

Based on the work above, five social sustainability principles can be arrived at, although further refinement on specific wording may be required for next iterations.

In a socially sustainable society, people are not subject to structural obstacles to ...

SSP 1....health.

SSP 2....influence.

SSP 3. ...competence.

SSP 4. ...impartiality.

SSP 5....meaning-making.

For each of these principles one can then derive questions that allow organizations to understand their current contribution to un-sustainability and plan to eliminate it. Below is an example set of what kind of questions may be asked based on the SSPs.

SSP1: What practices contribute to structural obstacles to peoples' health?

- Are there health and safety concerns for employees? For example, excessive working hours, unsafe or unhealthy work environments, harassment and abuse of workers, and forced labor/child labor.

- Are there contributions to insufficient living standards? For example, compensation/wages that do not allow for a basic decent living and prohibitive pricing of basic goods.

SSP2: What practices contribute to structural obstacles to peoples' influence on systems they are part of?

- Are there practices that suppress employees' influence within the organization? For example, no formal mechanisms to report up the command-chain, no acceptance of whistle-blowers and no bargaining rights.

- Are there practices that suppress, or rely on the lack of opportunity to express, the communities' opinion in relation to our work? For example, no formal mechanisms for the communities to give opinion and influence the aspects of the business that affect them.

- Are there practices that suppress, or rely on the lack of opportunity to express, the communities' opinion in relation to our activity in their community? For example, 
reliance on political regimes that engage in suppression of free speech and does not have free elections.

SSP3: What practices contribute to structural obstacles to peoples' competence?

- Are there insufficient learning or development mechanisms within the organization? For example, lack of opportunities for competence development, lack of mechanisms for organizational learning and development and no development talks.

- Are there practices that rely on, or promote, lack of education and competence development in the surrounding community? For example, operating in regions or countries that do not support educational development.

- Are there practices that promote false understanding? For example, false information and false advertising.

SSP4: What practices contribute to structural obstacles to peoples' impartial treatment?

- Are there practices of discrimination? For example, gender, racial or other discrimination.

- Are there practices that promote economic inequality? For example, extreme differences in income within the organization.

- Are there reliance on political regimes that support impartial treatment? For example, reliance on political regimes that engage in discrimination, engaging in corruption and relying on corrupt regimes.

SSP5: What practices contribute to structural obstacles to peoples' meaning-making?

- Is there lack of clarity within the organization? For example, lack of a clear purpose of the organization and lack of clear roles and responsibilities for individuals.

- Is there disrespect of employees' meaning-making? For example, not allowing a particular cultural expression in the workplace.

- Is there disrespect of the community's meaning-making? For example, disrespect of local culture and reliance on political regimes that engage in suppression of cultural expression.

- Is there reliance on practices that alter meaning-making subversively? For example, aggressive and misleading advertising.

- Are leaders inconsistent in relation to the purpose of the organization? For example, not 'walking the talk' and thereby putting a meaningful purpose in doubt.

\section{Discussion}


The research set out to derive useful social sustainability principles. The end result was a first hypothesis of five social sustainability principles to be used within the Framework for Strategic Sustainable Development. This section focuses on discussion and insights as regards the original aim and the FSSD approach and is a complement to the discussion in paper 1 of this two-part series.

An assessment against the characteristics for sustainability principles to be useful within the FSSD, i.e., for backcasting planning and redesign for sustainability (see Section 2), reveals the following: The research has built a logical argument for why these principles are necessary. Furthermore, having pursued extensive literature studies, the research at this point did not reveal any aspects related to complex adaptive social systems and social sustainability that could not be sub-ordered to the five principles, or fit elsewhere in the five level model of the FSSD. This implies that the current principles are sufficient based on current understanding. However, the FSSD has always and will always be subject to continuous development, so future modelling and action research may call for amendments. This has also been the case for the ecological principles as the current wording of the three ecological principles has evolved over time to be more and more precise and helpful for backcasting planning and redesign. The principles are also meant to be general in that they are applicable to any group, organization or community and yet concrete enough to guide planning, innovation and action, as well as selection, development and a coordinated use of supplementary methods, tools and other forms of support. The results of the action research with various practitioners (see Missimer et al. 2014) support the new principles' applicability along those lines. Finally, they are meant to be nonoverlapping in the sense that all aspects of one are not also covered by another. The research presented in this paper has made a theoretical argument for this. The action research seems to also support the notion that the principles are indeed nonoverlapping, as the practitioners did not seem to have major difficulties in brainstorming violations and clearly grouping them under one principle rather than another. Preliminary data from action research also point at a possibility to develop non-overlapping sets of indicators under each principle.

It is important to re-iterate some essential nuances of the approach.

The term "no structural obstacles" in each of the principle is key to understanding the approach. The focus is intentionally not on, e.g., health or influence per se, but about whether there are structural obstacles in the way of achieving them. There can still be sick and un-influential people in a very solid and vital social system for as long as their misery is not being caused by structural obstacles. This nuance is closely related to the next.

Boundary conditions are about phrasing what must inevitably be part of something referred to as "success". But understanding the boundary conditions for success is not the same as reaching success. You may understand the principles of success without necessarily reaching it. In addition, you may fill the boundary conditions with contents including other aspects of success.

Boundary conditions are designed to address problems and guide solutions at a high enough system level to be generic, while still being operational. As such they should be inclusive to cover all things that are relevant to discuss, so as to not forget essential aspects. But they should not contain such aspects, so as to not become prescriptive and undermine innovation in the contextually different environments of organizations 
and regions. This leads also to a re-emphasis of a point made in Paper 1. The FSSD is not a substitute for other approaches or insights from the social sciences regarding individual and collective wellbeing. It is merely a framework based on a systemsscience understanding of the social and ecological system and how human activity may be eroding it and thereby undermining the possibility for individual and collective wellbeing.

\subsection{An example of the process for deriving principles}

The results presented show only the preliminary final outcome of the modelling process. Section 2 aimed to describe the process that lead to this outcome in as much detail as possible; however, an example may serve to illustrate it further. It became clear from the trustworthiness literature that one mechanism of degradation of trust is disrespect for the integrity of a person, meaning disrespect of the right of each individual to avoid injury and illness (physically, mentally and emotionally) in the short and long term. In earlier phrasing the core research group used 'integrity' as the keyword for this mechanism. In an earlier publication (Missimer 2013, 31) this was described as in the vein of "the meaning of 'Unversehrtheit' in German. The adjective 'unversehrt' means without damage, injury or harm." However, even then it was already acknowledged that this term could lead to confusion as the term 'integrity' was also featured in the trustworthiness literature in the sense of moral connotation along the lines of honesty and consistency. Still, the research group felt that the focus on the absence of harm was in line with what was needed. However, throughout the work with partners, it became obvious that workshop participants continuously got confused by the word integrity and almost always associated it with the moral connotation. This led the core research group to decide to abandon that term and opted to use health instead as the keyword for this mechanism. On the other hand, this came with the need to specify a more narrow definition of health than, e.g., the World Health Organization definition, which states that "Health is a state of complete physical, mental and social wellbeing and not merely the absence of disease or infirmity (World Health Organization 2006)". The WHO definition is wider than the intended meaning of this mechanism. Using health as the keyword therefore also comes with some risk for confusion, but the core research group has seen this as the best option so far, together with a clarification of its specific meaning when this sustainability principle is first introduced to users of the FSSD, i.e.: in a socially sustainable society, people are not exposed to social conditions that systematically undermine their possibilities to avoid injury and illness, physically, mentally or emotionally. It should also be pointed out, again, that social sustainability does not mean that all people, or 'as many as possible', will be healthy or influential, or competent, etc. The principles are about whether or not power and norms imply obstacles for health, influence, competence, etc. The term 'structural obstacles to...' is key to each principle.

Finally, there are many other elements that appear in the literature on social sustainability. 'Empathy', e.g., a constitutional element of most peoples' mental makeup belongs to the systems level, sits at the first level of the five level model of the FSSD. To apply this capacity to put oneself in the shoes of other for the sake of doing good is called the Golden Rule. "Do not do to others what you do not want them to do you". This way of applying empathy can serve as an 'acid-test' on measures and strategies laid out to approach compliance with the sustainability 
principles, and thus is a form of strategic guideline which belongs to the third level. 'Transparency' most likely also belongs to the third level. Further elaborations along these lines will continue in future research; so will the development of indicators, under the fifth level.

\subsection{Implications of the results}

Section 3.3 highlights the many ways our current systems, especially the economic systems, currently contribute to social un-sustainability and that these are really not just one-off actions but design flaws of our basic systems. It is clear transformation in many of these systems is needed and also that transformability as an extension of adaptability (or included depending on how one defines adaptability) is an important feature of any system. This is why the FSSD focuses on essential aspects of the social system to be sustained, not the particular configuration that we have now. In this sense, the approach does not consider sustainable development as the perpetuation of the status quo, but as a path towards sustainability, where sustainability is defined by boundary conditions. Transitioning to compliance with these boundary conditions, and then to continue, e.g., social, cultural and technical development within those conditions, is how sustainable development is defined in this approach.

\subsection{Validity}

A theory is usually tested empirically for validation. Testing for validation is, however, harder for more abstract higher-level social theories and in dynamic systems. Blessing and Chakrabarti (2009) discuss the limitations of validating research that is based on creating something new and then testing it (often referred to as design (science) research), as it is often difficult to establish whether the desired effect was created by the specific intervention or another unaccounted for aspect. In addition, "the context in which the development process takes place changes, irrespective of the introduction of design support: people learn, markets change, organizations evolve, new technologies emerge, new knowledge becomes available and new regulations are put in place" (ibid, 183)". In that sense, preliminary testing regarding whether the proposed principles are applicable, understandable, relevant and helpful to people working in various fields has begun (see Missimer et al. 2014). It has not yet been tested what the longer-term results would be, which will need a more rigorous qualitative research approach and is an essential next step to validate and improve the conceptual model.

\section{Conclusion}

The social sustainability field is facing numerous challenges regarding vagueness and lack of actionable approaches, a debate over different sets of values, and suboptimization in the solution space due to a lack of systems approaches. Similarly, the FSSD also lacked a robust approach to the social dimension. 
This research began with the idea that the social dimension of the FSSD could benefit from further scientific support and elaboration. A prototype based on extensive literature studies and conceptual mental-modelling sessions was proposed. This prototype has since been tested with practitioners in various applications (Missimer et al., 2014). However, it is not possible to claim that social sustainability, even specifically within the FSSD, has been completely covered and dealt with at this point. As is common with research including elements of design, it will need testing and adjustment over time.

The approach presented in this paper attempts to overcome the challenges in the field. It aims to contribute a definition of social sustainability, which is general enough to be applied irrespective of spatial and temporal constraints, but concrete enough to guide decision-making and monitoring. This then can also provide a foundation for moving many other research and application fields forward as regards social sustainability, e.g., product-service innovation, supply-chain management and regional development. Efforts in this regard are already on their way (e.g., Gould et al. in this same issue, Mesquita et al. 2015, 2016) and in this way the research presented in this tandem paper is only the kick-start for much more research and development of practical support in the field of social sustainability.

\section{Acknowledgements}

Financial support was provided by the FUTURA foundation and is hereby gratefully acknowledged. FUTURA was not involved in the study design, the collection, analysis and interpretation of data, in the writing of the report or in the decision to submit the article for publication.

\section{References}

Amini, M. \& Bienstock, C.C. 2014. Corporate sustainability: an integrative definition and framework to evaluate corporate practice and guide academic research. Journal of Cleaner Production 76: 12-19.

Baier, A.1986. Trust and Antitrust. Ethics 96(2):231-260. Available at http://www.jstor.org/stable/2381376.

Ben-Eli, M. 2012. The cybernetics of sustainability: Definition and underlying principles." Enough for All forever: A Handbook for Learning about Sustainability, Murray J, Cawthorne G, Dey C and Andrew C (eds.). Champaign, IL, Common Ground Publishing: University of Illinois. Available at: http://www.sustainabilitylabs.org/files/The_Cybernetics_of_Sustainability\%20FF.p $\underline{\mathrm{df}}$

Bews, N. \& Martins, N. 2002. An evaluation of the facilitators of trustworthiness. $S A$ Journal of Industrial Psychology. 28 (4), pp.14-19.

Blessing, L. \& Chakrabarti, A. 2009. DRM, a Design Research Methodology. London: Springer Verlag. 
Boström, M. 2012. A missing pillar? Challenges in theorizing and practicing social sustainability: introduction to the special issue. Sustainability: Science, Practice, \& Policy. 8(1), pp. 3-14

Broman, G. \& Robèrt K.-H., 2015. A framework for strategic sustainable development (in this issue).

Brooks, R. J. 2007. Conceptual modelling: framework, principles, and future research. Working Paper 2007/011. Lancaster University Management School. http://eprints.lancs.ac.uk/48885/1/Document.pdf

Caldwell, C. \& Clapham, S.E. 2003. Organizational Trustworthiness: An International Perspective. Journal of Business Ethics 47, pp.349-364.

Castelfranchi, C. \& Falcone, R. 2010. Trust theory: A socio-cognitive and computational model. Vol. 18. John Wiley \& Sons.

Chasin, F. 2014. Sustainability: Are We All Talking About the Same Thing? Proceedings of the ICT for Sustainability, 342-351.

Colantonio, A., Dixon, T., Ganser, R., Carpenter, J., Ngombe, A., 2009. Measuring Socially Sustainable Urban Regeneration in Europe. Oxford Institute for Sustainable Development (OISD). School of the Built Environment, Oxford Brookes University.

Coleman, J. 1990. Foundations of Social Theory. The Belknap Press of Harvard University Press.

Collins, J.C. \& Porras, J.I. 2002. Built to last. ( $3^{\text {rd }}$ ed). New York: Harper Collins Publisher Inc.

Colquitt, J.A., Scott, B.A. \& J. A. LePine. 2007. Trust, trustworthiness, and trust propensity: a meta-analytic test of their unique relationships with risk taking and job performance. Journal of applied psychology. (92)4, pp. 909-927.

Cook, K. (ed.). 2001. Trust in society. Russell Sage Foundation.

Cuthill, M., 2010. Strengthening the 'Social' in sustainable development: developing a conceptual framework for social sustainability in a rapid urban growth region in Australia. Sustainable Development 18 (6), 362e373.

Davidson, M. 2009. Social sustainability: a potential for politics? Local Environment. 14:7, pp.607-619.

Dempsey, N., Bramley, G., Power, S. \& Brown, C. 2011. The social dimension of sustainable development: Defining urban social sustainability. Sustainable Development. 19(5), pp.289-300.

Engelbrecht, A.S. \& Cloete, B.E. 2000. An analysis of a supervisor-subordinate trust relationship. Journal of Industrial Psychology. 26 (1), pp.29-38.

Folke, C., Carpenter, S., Elmqvist, T., Gunderson, L., Holling, C. S., Walker, B., Bengtsson, J., Berkes, F., Colding, J., Danell, K., Falkenmark, M., Gordon, L., Kasperson, R., Kautsky, N., Kinzig, A., Levin, S., Mäler, K. G., Moberg, F., Olsson, P., Oström, E., Reid, W., Rockström, J., Savenije, H. \& Svedin, U. 2002. Resilience and Sustainable Development: Building Adaptive Capacity in a World of Transformations-Scientific Background Paper on Resilience for the process of The 
World Summit on Sustainable Development on behalf of The Environmental Advisory Council to the Swedish Government. Stockholm: Ministry of the Environment.

Fukuyama, F. 1995. Trust: The social virtues and the creation of prosperity. New York: Free Press

Fukuyama, F. 2002. Social Capital and Development: The Coming Agenda. SAIS Review. 20(1), pp. 23-37.

Gambetta, D. 2000. Can We Trust Trust? In: Gambetta, D. (ed.) Trust: Making and Breaking Cooperative Relations, electronic edition, Department of Sociology, University of Oxford, chapter 13, pp. 213-237.

Giddens, A. 1984. The Constitution of Society. Outline of the Theory of Structuration. Cambridge, UK: Polity Press.

Giddens, A. 1990. The Consequences of Modernity. Cambridge: Polity Press

Giddens, A. 1991. Modernity and Self-Identity: Self and society in the late modern age. Cambridge, UK: Polity Press.

Glavič, P. \& Lukman, R. 2007. Review of sustainability terms and their definitions. Journal of cleaner production 15.18: 1875-1885.

Gould, R. Missimer, M \&Mesquit, P.L. 2015. Analysing product concepts with respect to social sustainability: Learnings from designing support. in this issue

Hardin, R. (eds.). 2002. Trust and trustworthiness. Russell Sage Foundation. Hardin, R. 1996. Trustworthiness. Ethics. 107, pp.26-42.

Hodge, R.A. \& Hardi, P. 1997. The need for guidelines: the rationale underlying the Bellagio principles for assessment. In Assessing Sustainable Development. Principles in Practice. P. Hardi \& T. Zdan, eds. Winnipeg, Manitoba, CA: International Institute for Sustainable Development. pp.7-20.

Hollis, M. 1998. Trust within Reason. Cambridge: Cambridge University Press

Hopwood, B, Mellor, M. \& O'Brien, G. 2005. Sustainable development: mapping different approaches. Sustainable development 13.1: 38-52.

Huesemann, M. H. 2001. Can pollution problems be effectively solved by environmental science and technology? An analysis of critical limitations. Ecological Economics. 37(2), p.271-288.

Jaccard, J. \& Jacoby, J. 2010. Theory Construction and Model building skills. New York: Guilford press.

Jacobs, M. 1999. Sustainable development: a contested concept. In Fairness and futurity: essays on environmental sustainability and social justice. Dobson, A, ed. Oxford, UK: Oxford University Press.

Johnston, P., Everard, M., Santillo, D \& Robèrt, K.-H. 2007. Reclaiming the definition of sustainability. Environmental Science and Pollution Research. 14 (1): 60-66.

Jones, K. 1996. Trust as an affective attitude. Ethics. 107, pp.4-25.

Klinger, E. 1998. The search for meaning in evolutionary perspective and its clinical implications. In The Human Quest for Meaning: A Handbook of Psychological 
Research and Clinical Applications. Wong, P. \& Fry, P. (Eds.). New Jersey: Laurence Erlbaum Associates. pp. 27 - 50.

Kotiadis, K. \& Robinson S. Conceptual modelling: knowledge acquisition and model abstraction. Proceedings of the 40th Conference on Winter Simulation. Winter Simulation Conference, 2008.

Kramer, R. M. \& Tyler, T.R. (eds). 1996. Trust in organizations: Frontiers of Theory and Research. London: Sage

Kunz J. 2006. Social Sustainability and Community Involvement in Urban Planning. University of Tampere: Tampere, Finland.

Lagerroos, D. 2004. Sustainability Seen Through An Integral Lens. World Futures. 60(4), pp. $319-325$.

Lahno, B. 2001. On the emotional character of trust. Ethical Theory and Moral Practice 4:171-189

Lehtonen, M. 2004. The environmental-social interface of sustainable development: capabilities, social capital, institutions. Ecological Economics. 49(2), pp.199-214.

Littig, B., Griessler, E., 2005. Social sustainability: a catchword between political pragmatism and social theory. Int. J. Sustain. Develop. 8 (1), 65e79.

Lewis, J. D. \& Weigert, A. 1985. Trust as a social reality. Social Forces. 63, pp.967- 985 .

Lozano, R. 2008. Envisioning sustainability three-dimensionally. Journal of Cleaner Production 16.17: 1838-1846.

Luhman, N. 1995. Social Systems. Stanford, CA, USA: Stanford University Press

Luhmann, N. 1979. Trust and Power. John Wiley \& Sons.

Luhmann, N. 2000. Vertrauen, ein Mechanismus der Reduktion der sozialer Komplexität. 4. Auflage, Stuttgart: Lucius \& Lucius.

Marcuse, P. 1998. Sustainability is not enough. Environment and Urbanization. 10(2), pp.103-112.

Marsden, G. , Kimble, M. , Nellthorp, J. \& Kelly, C. 2010 Sustainability Assessment: The Definition Deficit. International Journal of Sustainable Transportation 4:4, 189 211

Mayer, R. C. \& Norman, P.M. 2004. Exploring Attributes Of Trustworthiness: A Classroom Exercise. Journal of Management Education. 28, pp.224-249.

Mayer, R. C. \& Gavin, M. B. 2005. Trust in management and performance: Who minds the shop while the employees watch the boss? Academy of Management Journal. 48, pp.874-888.

Mayer, R.C., Davis, J. H. \& Schoorman, F.D. 1995. An Integrative Model of Organizational Trust. Academy of Management Review. 20( 3), pp.709-734.

McKenzie, S. 2005. Building institutions for sustainability: A New Zealand case study. Diss. ResearchSpace@ Auckland.

McKenzie, S., 2004. Social Sustainability: Towards Some Definitions, Hawke 
Research Institute, Working Paper Series No. 27. University of South Australia.

McKnight, D. H., Cummings, L. L., \& Chervany, N. L. 1998. Initial trust formation in new organizational relationships. Academy of Management Review. 23(3), pp.473490.

McLeod, C. 2006. Trust. The Stanford Encyclopedia of Philosophy. Available at http://plato.stanford.edu/entries/trust

Meijboom, F. L. B., Visak, T. \& Brom, F.W.A. 2006. From Trust To

Trustworthiness: Why Information Is Not Enough In The Food Sector. Journal of Agricultural and Environmental Ethics. 19, pp.427-442.

Meijboom, F. L.B. 2008. Problems Of Trust: A Question of Trustworthiness An ethical inquiry of trust and trustworthiness in the context of the agricultural and food sector. Doctoral Dissertation, Utrecht University

Mesquita, P. L., Hallstedt, S., Broman, G. \& Isaksson, O. 2015. An introductory approach to concretize social sustainability for sustainable manufacturing. 11th International Symposium on Tools and Methods of Competitive Engineering, TMCE May, 2016. Accepted.

Mesquita, P.L., Svensson, M., Broman, G. \& Hallstedt, S. 2016. The use of sustainability principles to assess a product's social sustainability implications. Abstract accepted to NordDesign 2016, Trondheim, Norway

Missimer M, Robèrt K-H \& Broman G. 2015. A Strategic Approach to Social Sustainability - Part 1: Exploring the Social System (in this same issue).

Missimer M, Robèrt K-H, \& Broman G. 2014. "Lessons from the field: A first evaluation of working with the elaborated social dimension of the Framework for Strategic Sustainable Development". Presented at Relating Systems Thinking and Design 3. Oslo, 15 - 17 October 2014

Missimer M, Robèrt K-H, Broman G and Sverdrup H. 2010. Exploring the possibility of a systematic and generic approach to social sustainability. Journal of Cleaner Production 18(10-11):1107-1112

Missimer, M. 2013. The social dimension of strategic sustainable development. Licentiate Dissertation, Blekinge Institute of Technology.

Missimer, M. 2015. Social Sustainability within the Framework for Strategic Sustainable Development. Doctoral Dissertation, Blekinge Institute of Technology

Miztal, B. 1996. Trust in Modern Societies: The Search for the Bases of Social Order. Polity Press.

Ny H., MacDonald J.P., Broman G., Yamamoto R. \& Robèrt K-H. 2006. Sustainability constraints as system boundaries: an approach to making life-cycle management strategic. Journal of Industrial Ecology. 10(1-2), pp.61-77.

Nyquist Potter, N. 2002. How can I be trusted?: a virtue theory of trustworthiness. Lanham, Md. : Rowman \& Littlefield

Ostrom, E., Walker, J. \& Messner, D. 2003. Trust and reciprocity. Russel Sage Foundation. 
Partridge,E. 2005. Social sustainability: a useful theoretical framework? Paper presented at the Australasian Political Science Association Annual Conference 2005, Dunedin, New Zealand, 28-30 September 2005.

Putnam, R. 1993. Making democracy work. Civic traditions in modern Italy. Princeton (NJ): Princeton University Press

Putnam, R. 2000. Bowling Alone. The Collapse and Revival of American Community. New York, London: Simon and Schuster.

Robèrt, K-H. 2002. The Natural Step story: Seeding a quiet revolution. Gabriola Island: New Society Publishers. (see, e.g., page 107 and onwards)

Robèrt, K.-H., Schmidt-Bleek, B., Aloisi de Larderel, J., Basile, G., Jansen, J.L., Kuehr, R., Price Thomas, P., Suzuki, M., Hawken, P. \& Wackernagel, M. 2002. Strategic sustainable development selection, design and synergies of applied tools. Journal of Cleaner Production. 10, pp.197-214.

Robinson, S. 2006. Issues in conceptual modelling for simulation: setting a research agenda." Proceedings of the 2006 OR Society Simulation Workshop.

Rothstein, B. \& Stolle, D. 2008. The state and social capital: An institutional theory of generalized trust. Comparative Politics. 40(4), pp.441-459.

Rothstein, B. 2005. Social Traps and the problem of Trust. Cambridge: Cambridge University Press

Roy, S. K., \& Shekhar, V. 2010. Alternative Models of Trustworthiness of Service Providers. Journal of Global Marketing. 23(5), pp.371-386.

Schoorman, F. D., Mayer, R. C., \& Davis, J. H. 1996. Empowerment in Veterinary Clinics: The role of trust in delegation. Paper presented at Annual Meeting of Society for Industrial and Organizational Psychology, San Diego.

Schutz, W. 1958. FIRO: A Three-Dimensional Theory of Interpersonal Behavior. New York, NY: Rinehart.

Schutz, W. 1992. Beyond FIRO-B-Three New Theory Derived Measures-Element B: Behavior, Element F: Feelings, Element S: Self. Psychological Reports. 70, pp.915-937.

Schutz, W. 1994. The Human Element: Productivity, Self-Esteem and the Bottom Line. San Francisco, CA: Jossey-Bass.

Sztompka, P. 1999. Trust: A Sociological Theory. Cambridge University Press.

Tilly, C. 2005. Trust and rule. Cambridge University Press.

Tullberg, J. 2008. Trust -The importance of trustfulness versus trustworthiness. The Journal of Socio-Economics. 37, pp.2059-2071.

United Nations. 2015. Transforming our World: the 2030 agenda for sustainable development. A/RES/70/1.

Uslaner, E. 2002. The Moral Foundation of Trust. New York: Cambridge University Press.

Warren, M. E. 1999. Democracy and trust. Cambridge University Press.

Wilkinson, R.G \& Pickett, K. 2009. The Spirit Level. London: Bloomsbury Press. 
Wollebaek, D. \& Selle, P. 2008. Where does social capital come from? In The third sector in Europe. Osborne, S.P. (eds) NY, NY: Routledge Studies in the Management of Voluntary and Non-profit Organizations.

World Commission On Environment And Development. 1987. Our Common Future. [report of the ] World Comission on Environment and Development. Available at: http://www.un-documents.net/wced-ocf.htm (Accessed January 21st, 2013)

World Health Organization. 2006. Constitution of the World Health Organization - Basic Documents, Forty-fifth edition, Supplement, October 2006. 